\title{
Fiber-Optic Interferometric Sensors for Measurements of Pressure Fluctuations: Experimental Evaluation
}

Y. C. Cho and P. T. Soderman

January 1993

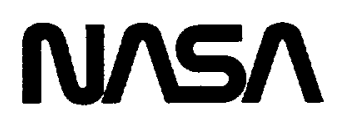

National Aeronautics and

Space Administration 



\title{
Fiber-Optic Interferometric Sensors for Measurements of Pressure Fluctuations: Experimental Evaluation
}

\author{
Y. C. Cho* and P. T. Soderman ${ }^{\dagger}$ \\ NASA Ames Research Center \\ Moffett Field, CA
}

\begin{abstract}
This paper addresses an ancchoic chamber cvaluation of a fiber-optic interferometric sensor (fibcr-optic microphone), which is being developed at NASA Ames Rescarch Center for measurements of pressure fluctuations in wind tunnels.

\section{Background}

Measurements of pressurc fluctuations in wind tunncl arc subject to certain interference effects, which affect currently existing transducer techniques. Such effects include wind noise, flow-sensor interaction noise, and flow induced sensor vibration. In an attcmpt to climinatc or minimize thesc interference effects, a program was undertaken at NASA Ames Research Center to develop a new advanced transducer technique ${ }^{1,2}$ using fiber-optic (FO) interferometric sensors. This sensor technology, initially developed for underwater acoustics, ${ }^{3-5}$ offers a number of advantages: high sensitivity, wide dynamic range, compact sensor package, light weight, geometric versatility, tclcmetry capability, and high temperature tolerance. These advantages can be utilized to solve the various noise problems that restrict the use of conventional transducers in wind tunncls or in harsh environments. Furthermore, FO sensors are immunc to electromagnetic interference.
\end{abstract}

\section{Fiber-Optic Interferometric Sensor}

The FO interferometric sensor utilizes the property that light waves propagating through the optical fiber undergo phase modulation when the fiber is exposed to external fields such as pressure and temperature. ${ }^{6}$ This phase modulation is interferometrically retrieved and processed to determine the external ficlds. Frequently used for acoustic measurements are Mach Zchnder interferometry 4,5 and Michelson interferometry. ${ }^{7}$

\footnotetext{
- Aerospace Engineer/Project Leader, Information Sciences Division.

${ }^{\dagger}$ Group Leader, Acroacoustics and Test Technique, Fixed-Wing Acrodynamies Branch. Member AIAA.

Copyright (C) 1993 by the American Institutc of Acronautics and Astronautics, Inc. No copyright is asserted in the United States under Title 17, U.S. Code. The U.S. Government has a royalty-free liecnse to excreise all rights under the copyright claimed herein for Governmental purposes. All other rights are reserved by the copyright owner.
}

As the first phase of the advanced sensor program at NASA Ames, the FO Mach Zehnder interferometry as displayed schematically in Fig. 1 was employed to develop and fabricate an FO sensor. This sensor is composed of three main elements: a laser with a pulse generator, two FO sensor hcads, and the optical detector with signal processors. ${ }^{2}$ Preliminary test results demonstrated feasibility of this sensor for aeroacoustic measurements. Extensive laboratory tests are in progress for evaluation of acoustic characteristics including acoustic sensitivity, dynamic range, frequency response, antenna focusing, and airborne noise rejection capability. Preliminary test results were reported in Ref. 2. Also reported were some additional data regarding this sensor, including the principle and the system devclopment.

\section{Test Setup}

For an experimental evaluation of the FO sensor, one sensor head was selected as the FO microphone, and its response was measured relative to a Brüel \& Kjaer (B\&K) condenser microphone exposed to the same acoustic field in the National Full-Scalc Acrodynamic Complex (NFAC) Anechoic Chamber. The anechoic chamber shown schematically in Fig. 2 has the dimensions $7.6 \times 5.5 \times 4.0 \mathrm{~m}$. The polyurethane wedges create an anechoic space of free ficld with an uncertainty of $\pm 0.5 \mathrm{~dB}$ for frequencics above $150 \mathrm{~Hz}$. Potential floor grid reflections were prevented by placing loose wedges between the loudspeaker and the microphones.

The FO and reference $B \& K$ microphones were cantilcvered from the same strut of $2.5 \mathrm{~cm}$ diameter, as shown in Fig. 3. The two microphoncs were separated by $10.2 \mathrm{~cm}$ vertically, and their median height was approximately the same as that of the loudspeaker center, which was $1.56 \mathrm{~m}$ above the floor grid. The loudspeaker was a $30.5 \mathrm{~cm}$ diamcter woofer, positioned $3.25 \mathrm{~m}$ from the microphones and aimed at them. The reference microphone was a $1.27 \mathrm{~cm}$ diametcr B\&K 4133 condenser microphone on which a bullet-shaped nose cone was mounted in anticipation of flow studies in the future.

The woofer was driven by a Hewlett-Packard (HP) 3562A swept-sine signal synchronized with the data analysis and operated at frequencies between $100 \mathrm{~Hz}$ and $2 \mathrm{kHz}$ for most of the test. The system was set so that the woofer was driven with a signal whose output started with $2 \mathrm{~V}$ rms at 
$100 \mathrm{~Hz}$ and decreased linearly to $1 \mathrm{~V}$ rms at $2 \mathrm{kHz}$. The signal generation was consistent from run to run. The microphone signals were input to the two-channcl spectrum analyzer (HP 3562A), which computed the power spectra and the cross spectrum of the two microphone signals.

Tests were performed for various FO sensor heads displayed in Plates I and II over the frequency range from $100 \mathrm{~Hz}$ to $2 \mathrm{kHz}$. Each sensor head was madc of optical fiber wound around a circular cylinder of styrofoam or aluminum, or an aluminum pipe. The optical fiber was of single mode and $8 \mathrm{~m}$ long. Some sensor heads were made of the single mode fiber coated with acoustically sensitive material. The frequency range was dictated by the electronic limitation of the demodulator, which is a signal processing component of the FO sensor. The demodulator was designed and fabricated by Litton for the Naval Research Laboratory, ${ }^{5}$ and its frequency response is shown in Fig. 4.

\section{Test Results}

Of the various FO scnsor heads tested, results arc presented for the following two cases: the first sensor head is composed of the $8 \mathrm{~m}$ long coated single-mode fiber wound around a circular cylinder of styrofoam. The cylinder was $6.4 \mathrm{~cm}$ long and $4.8 \mathrm{~cm}$ in diametcr, and the sensing scgment was $3.75 \mathrm{~cm}$ long. This sensor head will be referred to as Styrofoam FO microphone. The second sensor head is composed of the $8 \mathrm{~m}$ long coated single-mode fiber wound around an aerodynamically smooth aluminum body as shown in Plate 1l. This model is torpedo-shaped with circular cross-scction of $3.18 \mathrm{~cm}$ diameter at the sensing segment, which is $5 \mathrm{~cm}$ long. This sensor head will be referred to as Al-model FO microphone. The Styrofoam FO sensor head demonstrated the best performance of all the sensor heads tested, but is not suited for wind tunnel application without design revisions. The Al-model sensor head is the best suited for wind tunncl applications.

The results will be presented in terms of three parametric functions: frequency response function, power spectra, and noise floor. The frequency response function is evaluated by means of the transfer function, ${ }^{8}$ which is defincd as

$$
H_{f b}(f)=\frac{G_{f b}}{G_{b b}}
$$

Here $G_{b b}$ is the acoustic power spectrum of the B\&K microphone signal, and $G_{f b}$ is the cross spectrum of the two signals. On the assumption of uniform frequency responsc of the B\&K microphone, its signal spectrum is regarded as a faithful representation of the acoustic source field. The frequency response function of an $\mathrm{FO}$ microphone is then obtained as the transfer function $H_{f b}(f)$ with its magnitude being the gain factor over the B\&K microphone signal.

The frequency response function is the most important parameter for evaluation of the FO microphones. As defined in Eq. (1), it provides a systematic comparison of the FO microphone performance with the reference $B \& K$ microphone, and does not depend on acoustic source ficld spectrum. The power spectra will yield information on the frequency dependence of the source fields, but provide rather a supcrficial comparison of the two microphone performances. The noise floor will provide information on the signal-to-noise ratio of the microphones.

Displayed in Fig. 5 is the frequency response function of the Styrofoam FO microphone. Its magnitude, as displayed as the gain factor in Part $a$, is stable with a fluctuation of less than $\pm 1.5 \mathrm{~dB}$ around the average value. The average value is $30 \mathrm{~dB}$ at low frequencies, and decreases by about $2 \mathrm{~dB}$ as the frequency reaches $2 \mathrm{kHz}$. This decrease is caused by the demodulator gain factor as shown in Fig. 4a. The sharp deviation from the average appears at two frequencics, $180 \mathrm{~Hz}$ and $300 \mathrm{~Hz}$. This deviation is, as we belicve, duc to contaminated measurements by the reference $B \& K$ microphone. As can be seen from the display in Fig. 9c, the B\&K microphone yields spurious signal outputs which are almost $40 \mathrm{~dB}$ above the noise floor at the frequency $60 \mathrm{~Hz}$ and at its harmonics, $180 \mathrm{~Hz}$ and $300 \mathrm{~Hz}$. These signals werc apparently generated electronically by the AC power of $60 \mathrm{~Hz}$.

The phase, as displayed in Part $b$, decreases almost linearly with increasing frequency at a rate of 0.16 degree $/ \mathrm{Hz}$. This phase is none other than the phase difference between acoustic ficlds measured by the two microphones plus the clectronic phase of the instrumentation. The clectronic phase, which is controlled solely by the demodulator in the present study, also decreases at a rate of 0.16 degree $/ \mathrm{Hz}$ as seen from Fig. 4b. The phase difference between the acoustic ficlds measured by the two microphones is then constant over the cntire cvaluation frequency range, and this finding warrants that there exists an excellent correlation between the two measurements, and confirms the validity of the gain factor in Part a.

Displayed in Fig. 6 are power spectra of the acoustic signals detected by the Styrofoam FO and the B\&K microphoncs. The output of the microphones was the root mean squared value of the electric voltage. A scale factor $20 \mathrm{~dB}$ was used to convert the output voltage to the pressure level. An additional adjustment was made for the FO microphone by subtracting the gain factor $30 \mathrm{~dB}$ so that both microphoncs read approximately the same average level. Note that the net adjustment from the electric voltage output to the pressure level reading was $-10 \mathrm{~dB}$ for the FO microphone. Fairly good agreement is shown between the performances of the two microphones except at frequencies $180 \mathrm{~Hz}$ and $300 \mathrm{~Hz}$, where the B\&K microphone measurements were contaminated by the electric power oscillation as discussed earlier. Besides these spurious signals, the spectral shape of the B\&K microphone measurement is the same as that of the acoustic source field as long as this microphone frequency response is uniform as assumed. The FO microphone measurement shows fluctuations around the average with the amplitude less than $\pm 1.5 \mathrm{~dB}$. 
Displayed in Fig. 7 is the frequency response function of the Al-model FO microphone. The gain factor, as displayed in Part a, fluctuates around the average valuc with the amplitude 3 to $5 \mathrm{~dB}$. The average is $20 \mathrm{~dB}$ at low frequencies and gradually decreases to $13 \mathrm{~dB}$ at $2 \mathrm{kHz}$. When compared with the result in Fig. 5a, this FO microphone is less sensitive than the Styrofoam FO microphonc. The difference varies from $10 \mathrm{~dB}$ at low frequencies to $15 \mathrm{~dB}$ ncar $2 \mathrm{kHz}$. The phase, as displaycd in Part $b$, is fairly stable and lincarly decreases at a ratc of 0.17 degree/ $/ \mathrm{Hz}$. Accounting for the electronic phase decrease, the phase difference between the acoustic fields measured by the two microphones in this case changes at a ratc of $0.01 \mathrm{dcgrcc} / \mathrm{Hz}$. This phase stability warrants that there exists a good correlation between the acoustic ficld measurements by the $\mathrm{Al}$-model $\mathrm{FO}$ and the $\mathrm{B} \& \mathrm{~K}$ microphones and thus confirms the validity of the gain factor in Part a.

Displayed in Fig. 8 are power spectra of the acoustic signals detected by the Al-Model FO and the B\&K microphones. The output of the B\&K microphone was converted from the electric voltage to the pressure level by moving the curve upward by $20 \mathrm{~dB}$. The FO microphone output was moved upward by $3 \mathrm{~dB}$ as its avcrage gain factor is about $17 \mathrm{~dB}$ at $1 \mathrm{kHz}$. The FO microphonc measurement fluctuatcs around the avcrage with the amplitude varying from 3 to $5 \mathrm{~dB}$. The average appears to be in good agreement with the B\&K microphone measurements.

Displayed in Fig. 9 is the noise floor of the two FO microphones in Parts $a$ and $b$, and of the B\&K microphone in Part c. A singlc-tonc noisc source of $700 \mathrm{~Hz}$ was present during the measurements, and its output signals are marked with a circle. The noise floor is flat for all three microphones for frequencies from $200 \mathrm{~Hz}$ to $2 \mathrm{kHz}$. For frequencics below $200 \mathrm{~Hz}$, the NFAC Ancchoic chamber is not well insulated. The scalc of the noisc floor was adjusted to read the same pressurc level of the $700 \mathrm{~Hz}$ single-tone source field. The noise floor is about the same for the Styrofoam FO and the B\&K microphones with the signal-to-noise ratio of 32 or $33 \mathrm{~dB}$. The noise floor of the Al-Model FO microphone is higher than the other two by 12 to $13 \mathrm{~dB}$, corresponding to the signal-to-noisc ratio of $20 \mathrm{~dB}$. This difference is expected as the acoustic sensitivity of the $A l-M o d e l$ FO microphone is lower than the Styrofoam FO microphone by 10 to $15 \mathrm{~dB}$. As displayed in Part $c$, the B\&K microphonc output contains spurious single-tone signals at $60 \mathrm{~Hz}$ and then at every increment of $120 \mathrm{~Hz}$. As discussed earlier, these signals were electronically generated by the AC power.

The performance of the Styrofoam FO microphone is comparable to the reference B\&K microphonc. However, this FO microphone is not suitcd for wind tunncl testing without design modifications. The $A l-M$ odel FO did not perform as well as the other microphones mainly in two aspects as follows: First, its acoustic sensitivity was lower by 10 to $15 \mathrm{~dB}$, affording the smaller signal-to-noisc ratio. Second, the frequency dependence of its gain factor fluctuates excessively with the amplitude varying 3 to $5 \mathrm{~dB}$. This fluctuation is a form of noise which may have been generated by optical phase fluctuation randomly depending on the acoustic frequency. Further investigation is required to account for such noise. Nevertheless, we believe that such noise can be reduced with an improved design of the delay fiber as well as the sensing fiber. With the optical phase fluctuation removed, the signal-to-noise ratio can be enhanced by 6 to $8 \mathrm{~dB}$. Further improvement can be achieved with improved design of the demodulator.

The sensitivity difference between the two FO microphones is due to the styrofoam cylinder. It is acoustically compliant so that, when exposed to the acoustic ficld, the axial strain may be induced on the optical fiber wound around it. The $10 \mathrm{~dB}$ difference in sensitivity indicates that this styrofoam-induced strain is the dominant factor for the optical phase modulation of the styrofoam FO sensor, whereas the clasticity of the fiber coatings is the principal factor which allows pressure fluctuations to induce strains radially as well as axially for the Al-Model FO microphone. Despite its shortcomings, the Al-Model FO microphone is preferred as it is better suited for wind tunnel applications, and its performance can be improved as alluded to carlier.

\section{Concluding Remarks and Future Efforts}

The preliminary evaluation demonstrates successfully that the FO interferometric sensor can be used as aeroacoustic sensors. With the advantages described carlicr, the FO interferometric sensor array may provide a powerful instrument to solve complex acoustic measurement problems in wind tunnels.

Proper evaluation of performance of the FO interferometric sensors requircs further tests in an ancchoic chamber as well as in a wind tunnel, with revised designs and improved packaging of sensor heads. New demodulators will be designed to accommodate frequencies up to $10 \mathrm{kHz}$, and multiple sensor heads will be developed to improve the signal-to-noise ratio as displayed schematically in Fig. 10.

\section{References}

${ }^{1}$ Cho, Y. C., "Sensor Development Programs at NASA Ames Research Center," SPIE Proc., Vol. 1100, 1989, pp. $1-6$.

${ }^{2}$ Cho, Y. C., "FO Interferometric Acoustic Sensors for Wind Tunncl Applications," SPIE Paper 1795-04, SPIE's International Symposium OE/Fibers '92, Boston, MA, September 8-11, 1992.

${ }^{3}$ Giallorenz, T. G., Bucaro, J. A., Dandridge, A., Sigel, G. H. Jr., Colc, J. H., Rashlcigh, S. C., and Priest, R. G., "Optical Fibcr Scnsor Tcchnology," IEEE J. Quantum Electronics, Vol. QE-18, 1982, pp. 626-665.

${ }^{4}$ Brooks, J. L., Moslehi, B., Kim, B. Y., and Shaw, H. J., "Time-Domain Addressing of Remote FO Interferometric Scnsors Arrays," J. Lightwave Technology, Vol. LT-5, 1987, pp. 1014-1023. 
${ }^{5}$ Layton, M. R., “A Time Division Multiplexed Fiber Optic Sensor Networks," Vol. 1: Technical Report preparcd for Naval Rescarch Laboratory, Washington, D. C., Contracı No. N00014-87-C-2027, Junc 1987.

${ }^{6}$ Budiansky, B., Drucker, D. C., Kino, G. S., and Rice, J. R., "Pressure Sensitivity of a Clad Optical Fiber," Applied Optics, Vol. 18, 1979, p. 4085.
${ }^{7}$ Marrone, M. J., Kersey, A. D., and Dandridge, A., "Fiber Optic Michelson Array with Passive Elimination of Polarization Fading and Source Isolation," presented at 8th Optical Fiber Sensors Conference, Montercy, CA, January 29-31, 1992.

${ }^{8}$ Bendat, J. S. and Piersol, A. G., Engineering Applications of Correlation and Spectral Analysis, John Wiley \& Sons, New York, 1980.

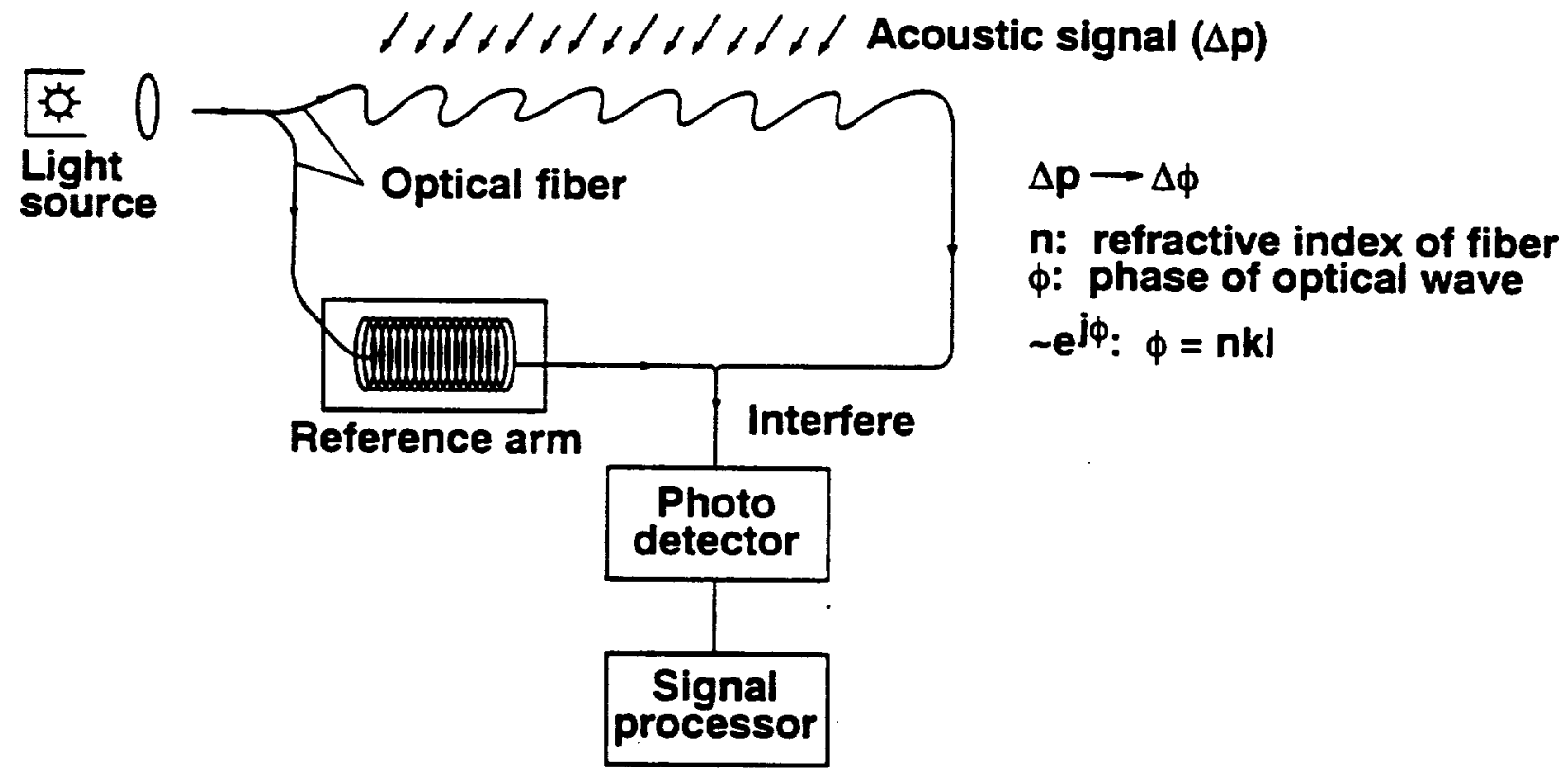

Fig. 1 Fiber-optic Mach Zehnder interferometry for acoustic sensors. 


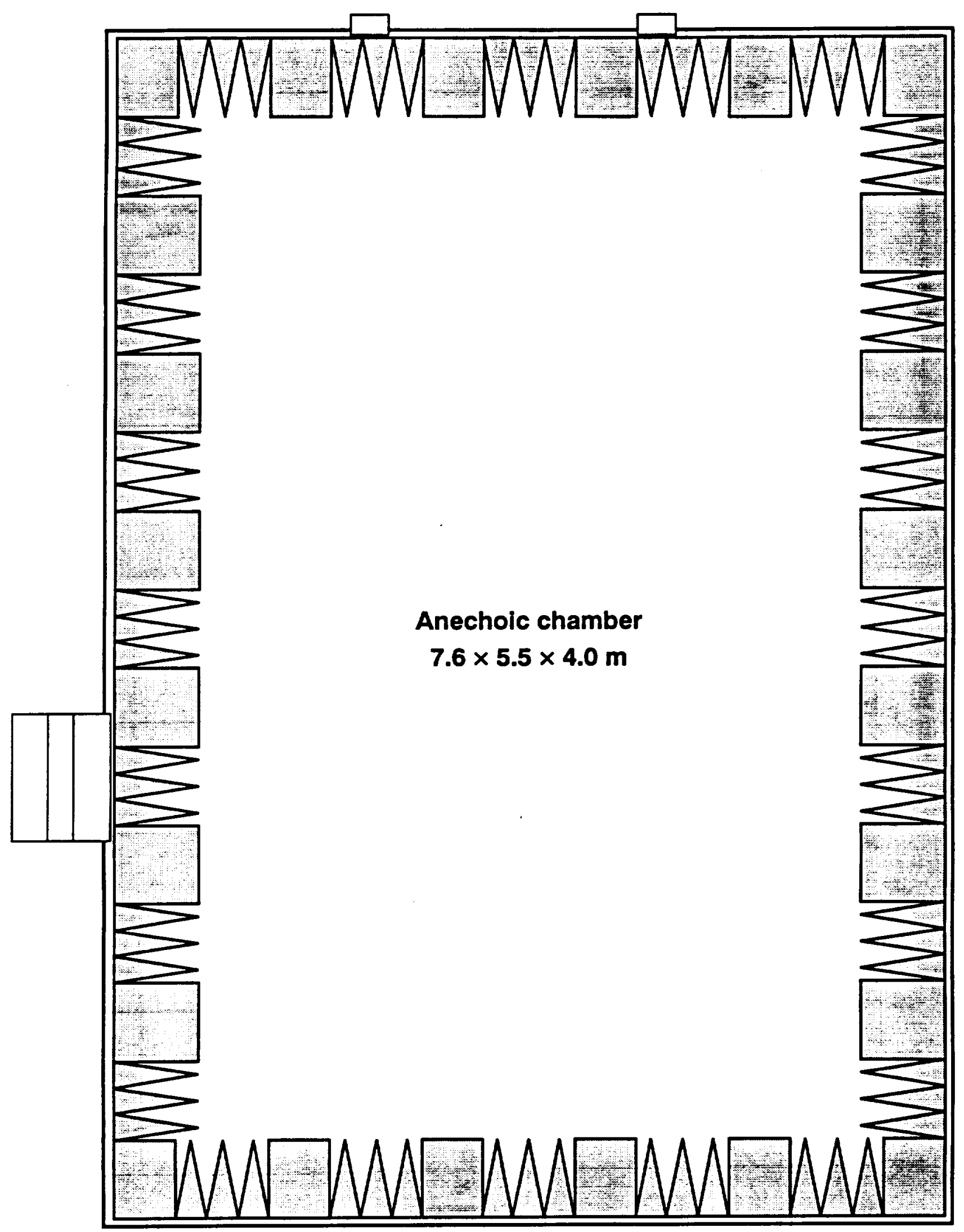

Fig. 2 Plan view of NFAC Anechoic Chamber. 


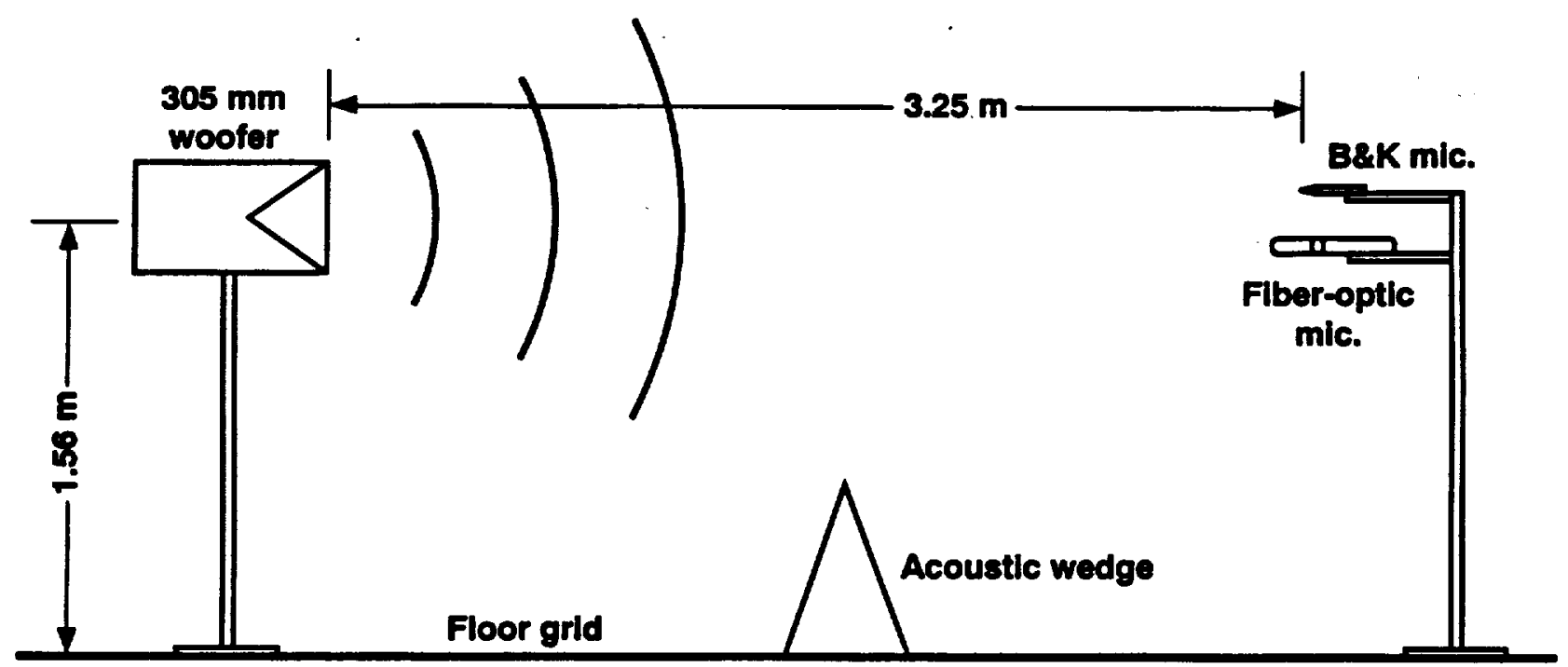

Fig. 3 Arrangement of speaker and microphones for anechoic chamber test.

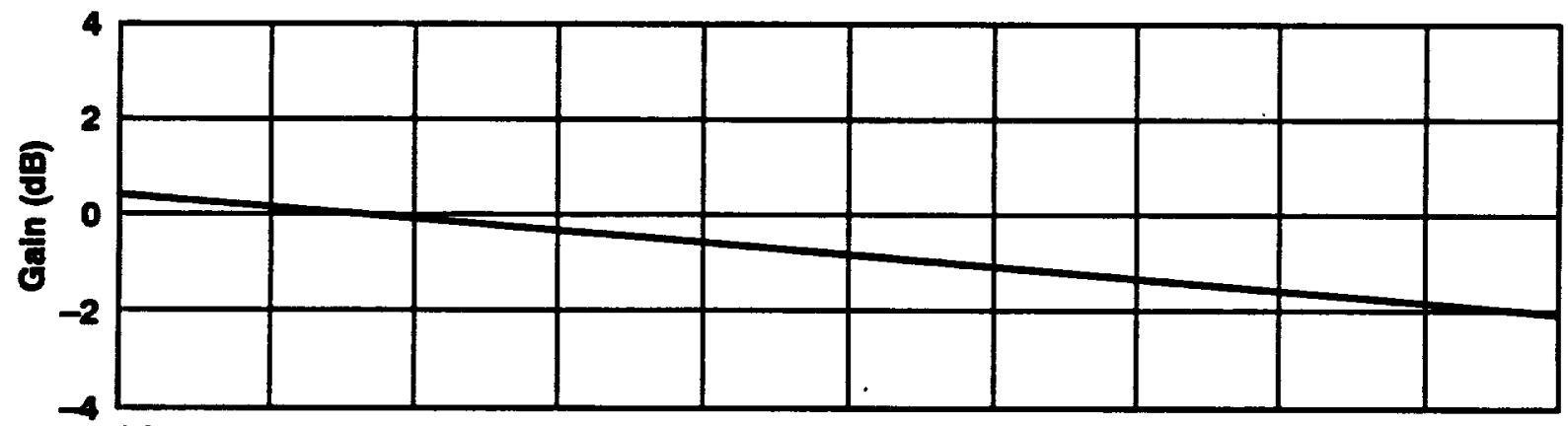

(a)

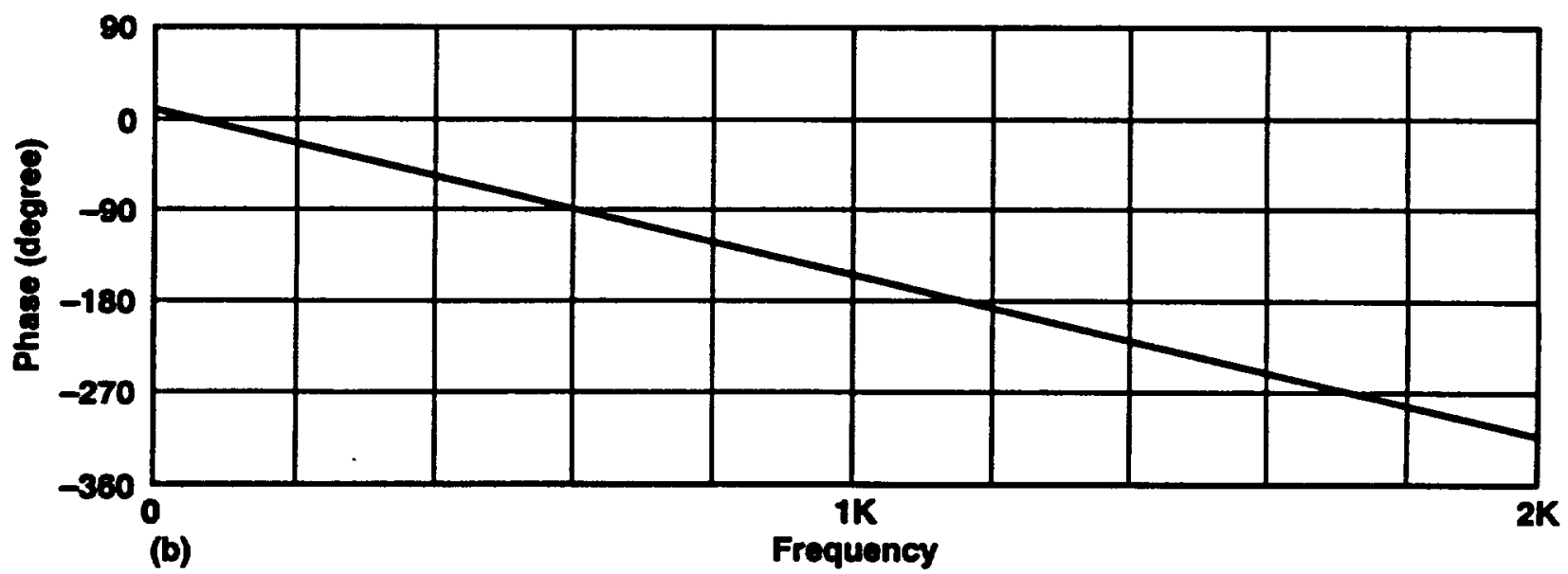

Fig. 4 Frequency response function of demodulator. a) Magnitude, b) phase. 


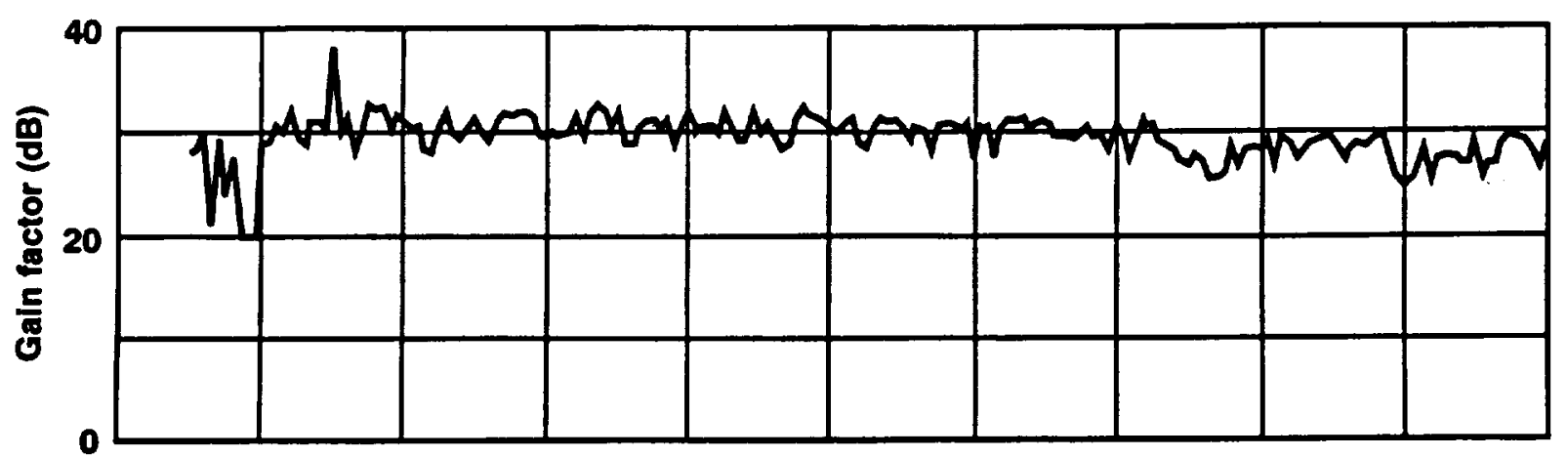

(a)

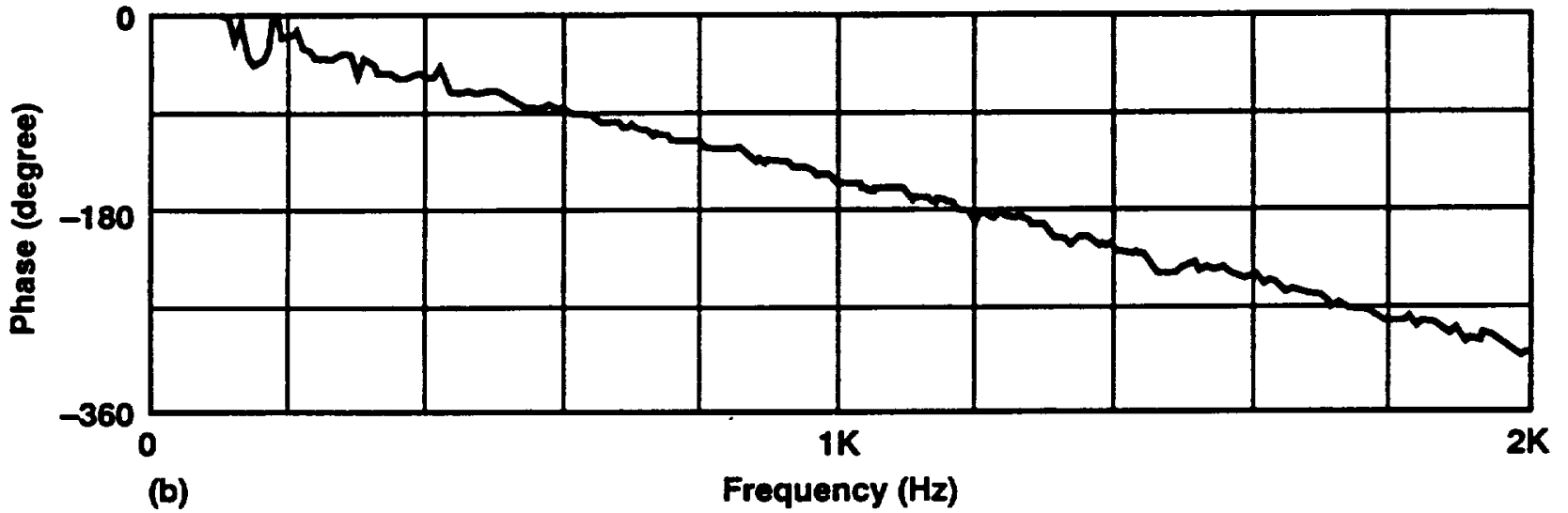

Fig. 5 Frequency response function of Styrofoam fiber-optic microphone. a) Magnitude - gain factor over B\&K microphone, b) phase.

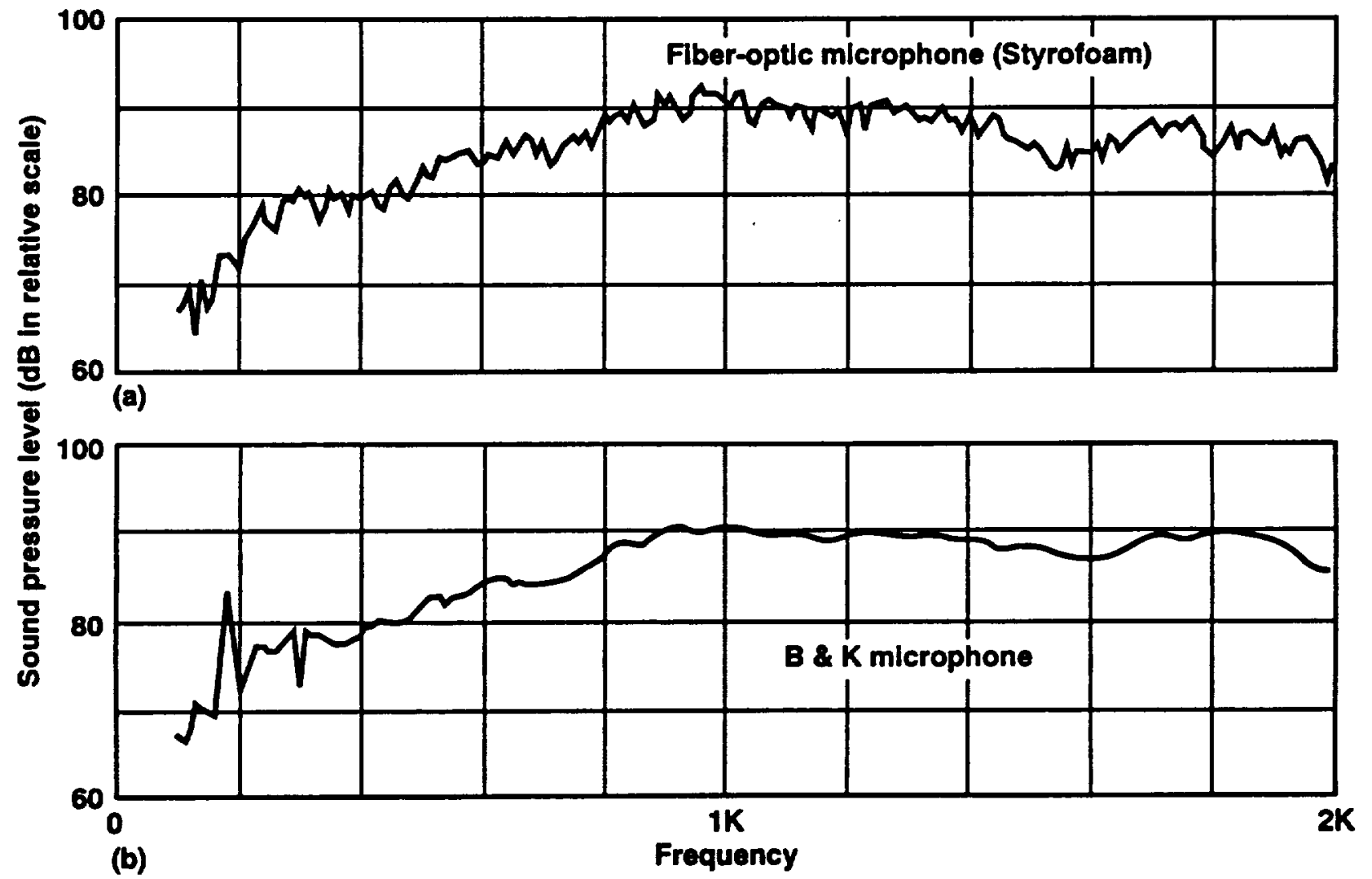

Fig. 6 Sound pressure level vs. frequency for Styrofoam fiber-optic and B\&K microphones. 


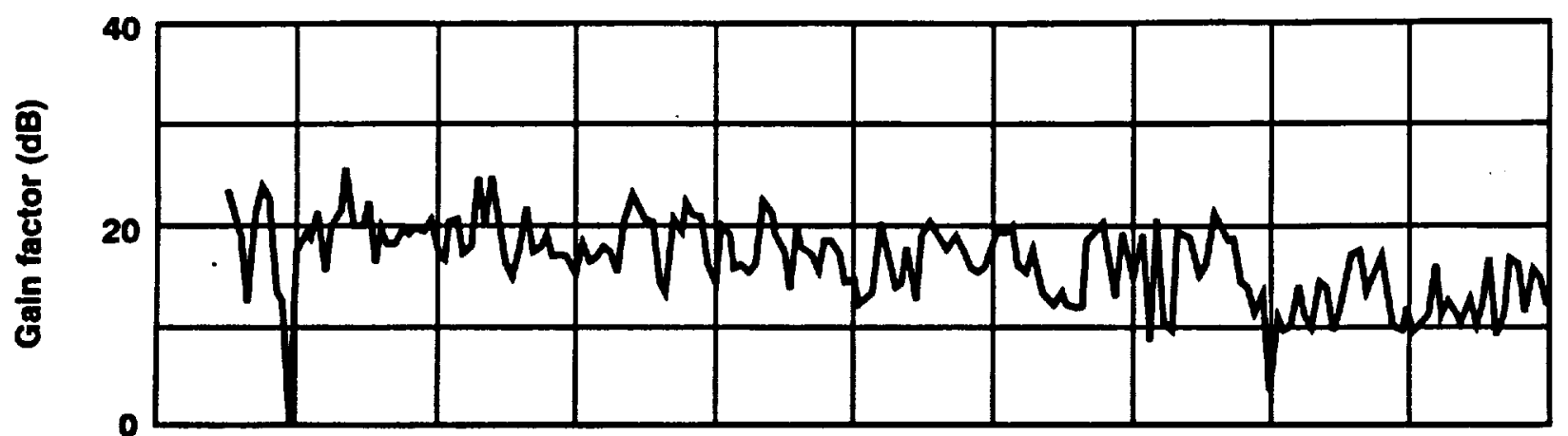

(a)

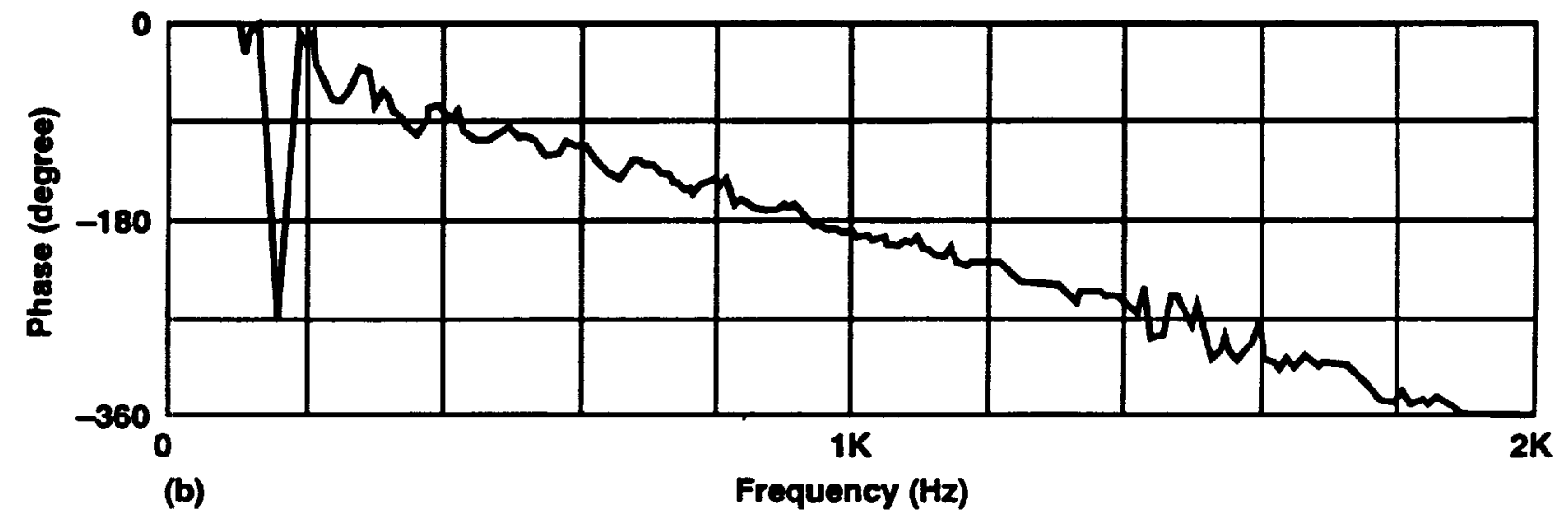

Fig. 7 Frequency response function of Al-Model fiber-optic microphone. a) Magnitude - gain factor over B\&K microphone, b) phase.

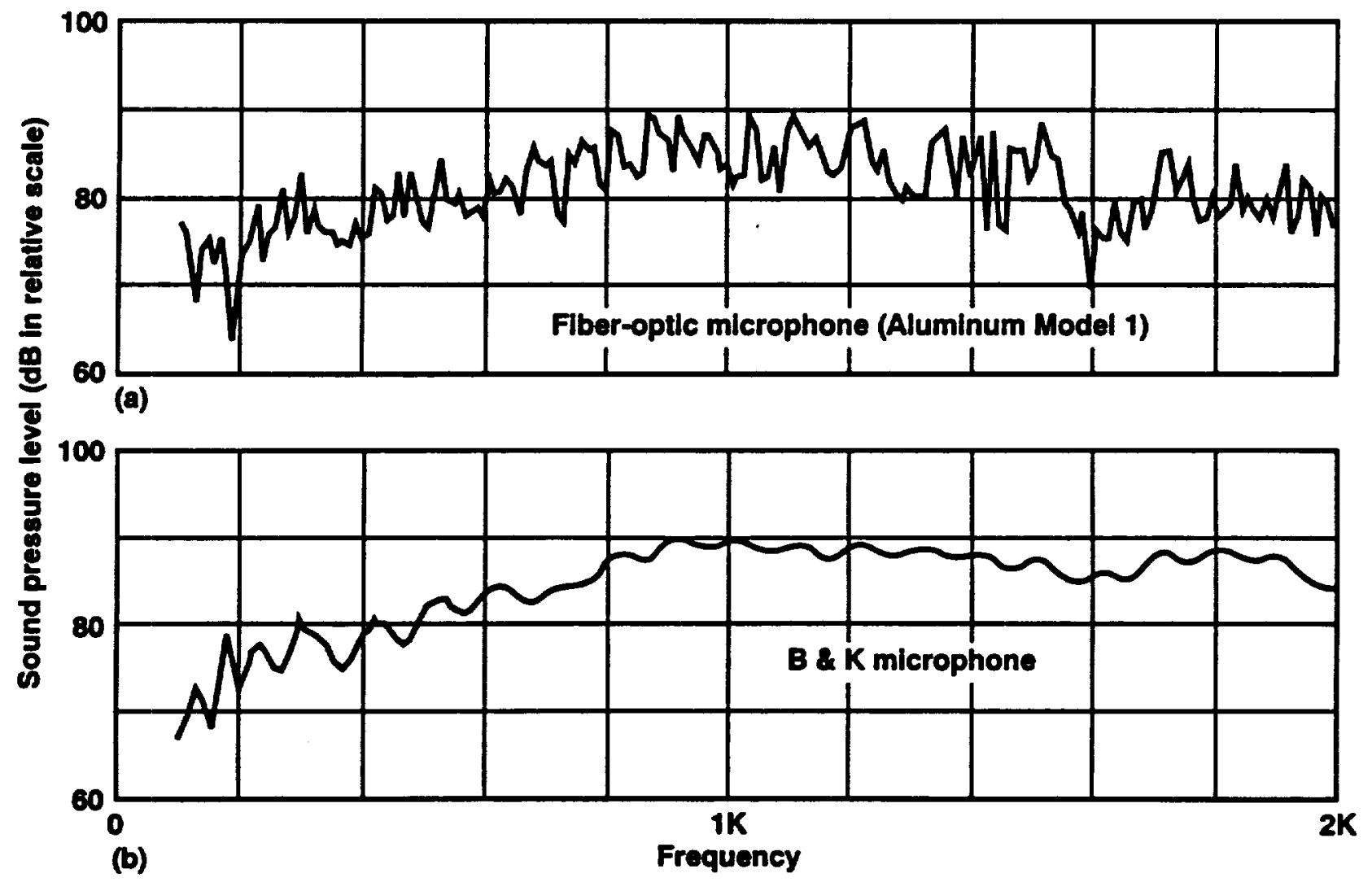

Fig. 8 Sound pressure level vs. frequency for Al-Model fiber-optic and B\&K microphones. 


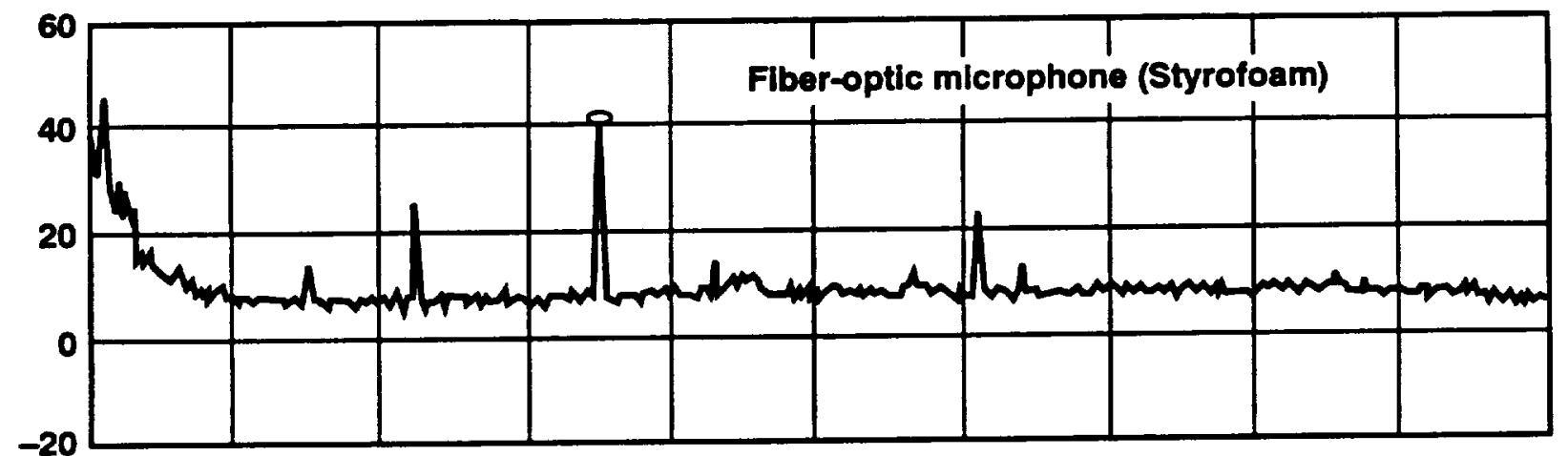

(a)

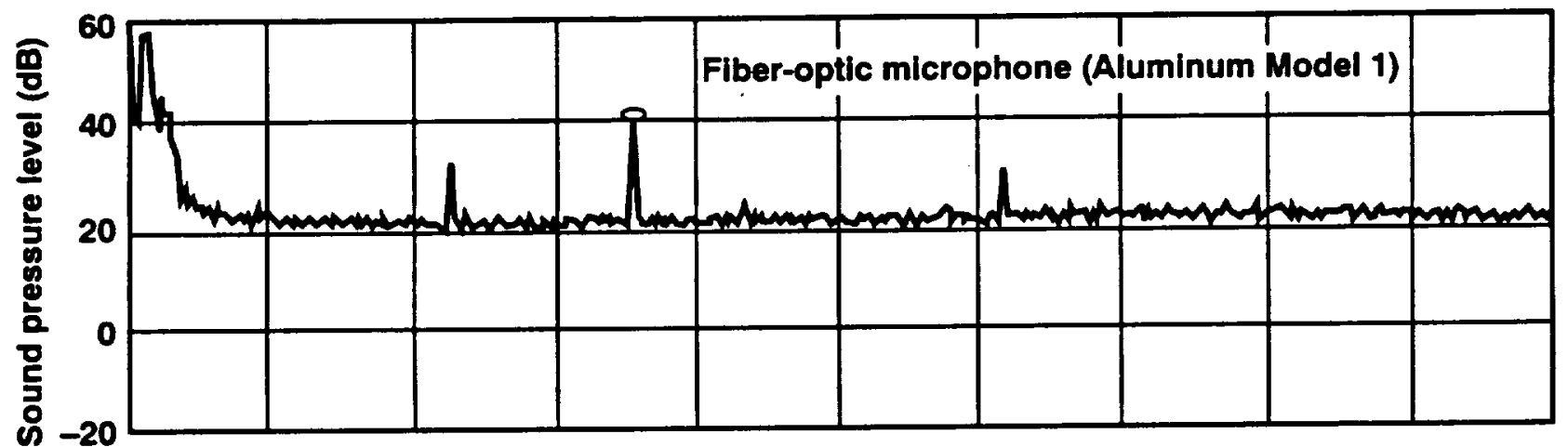

(b)

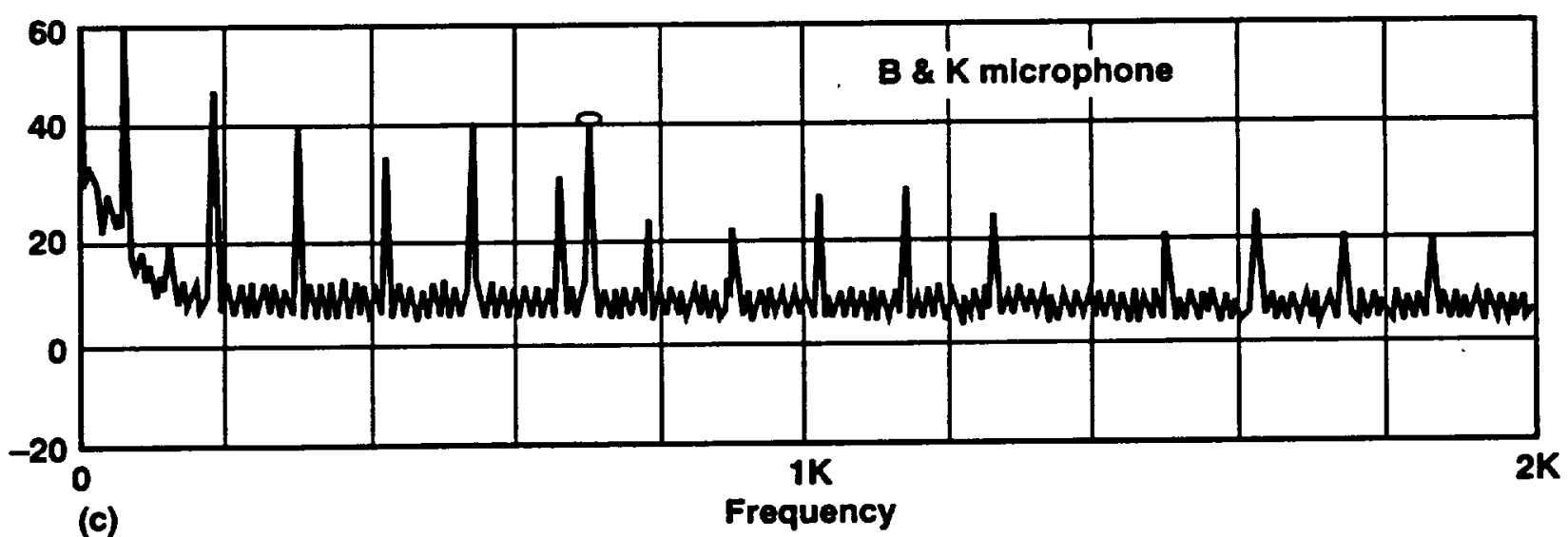

Fig. 9 Noise floor of two fiber-optic and B\&K microphones. 

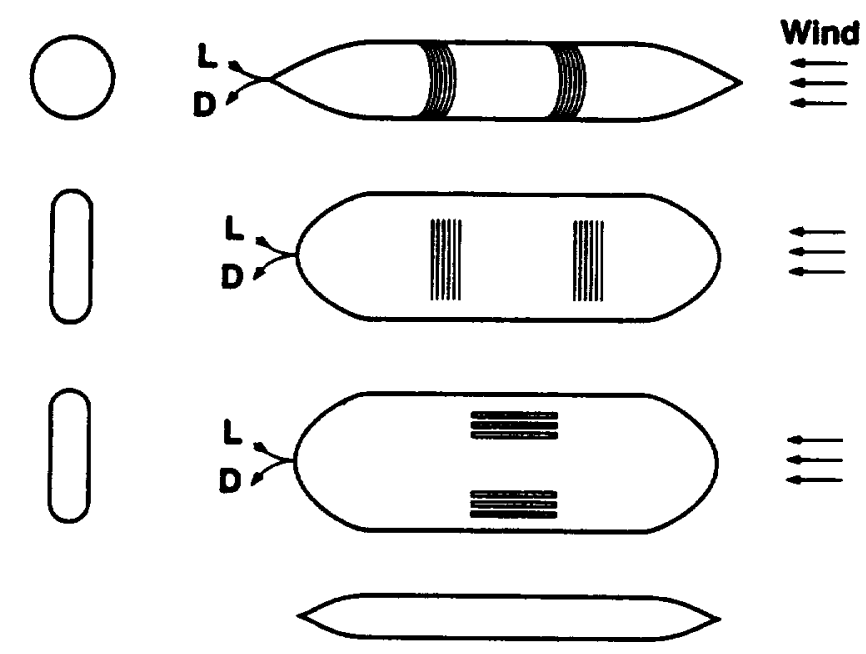

Fig. 10 Design of various sensor heads for wind tunnel applications. 


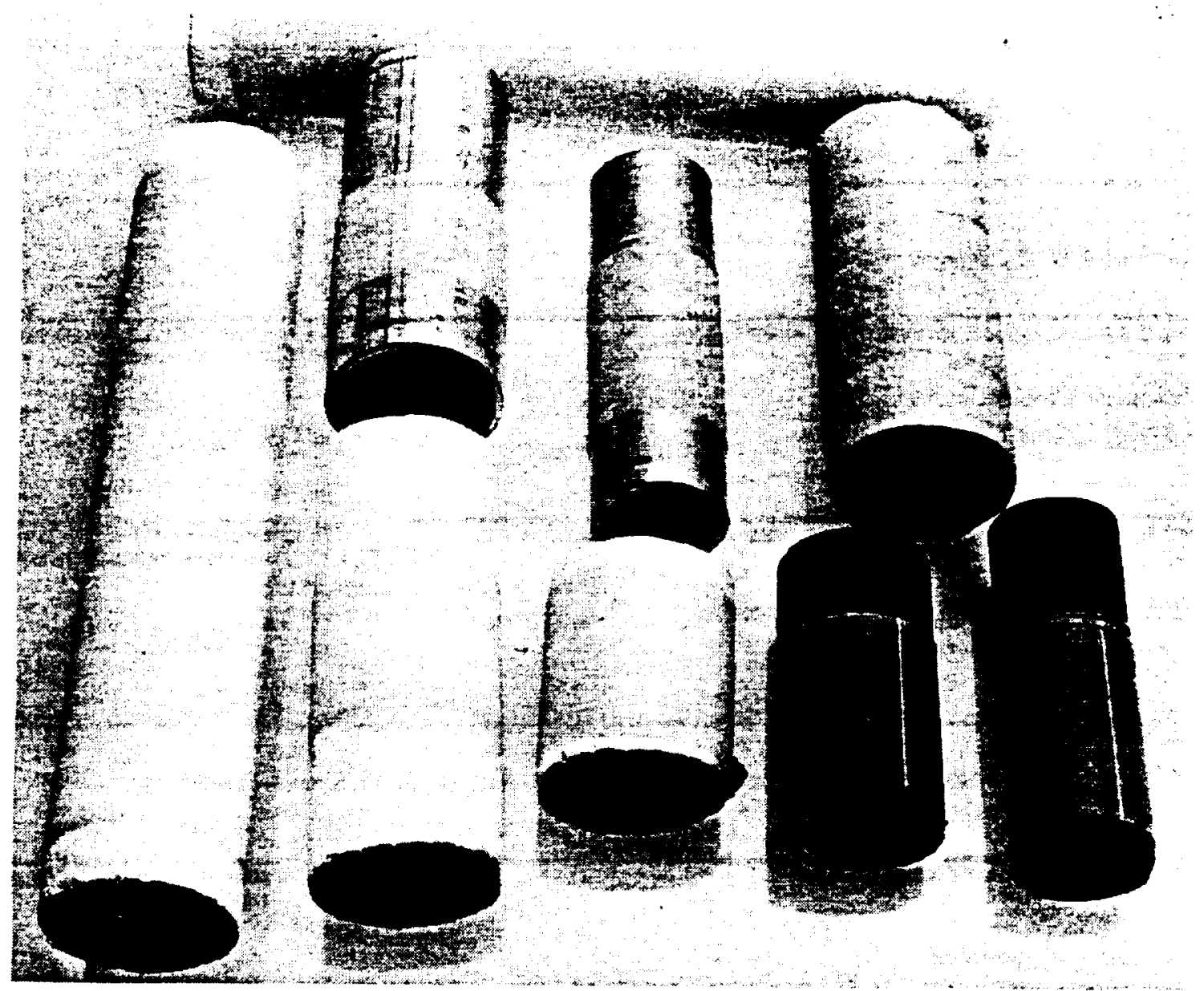

Plate I Sensor heads made of specialty single mode fiber wound around aluminium pipes or circular cylinders of styrofoam.

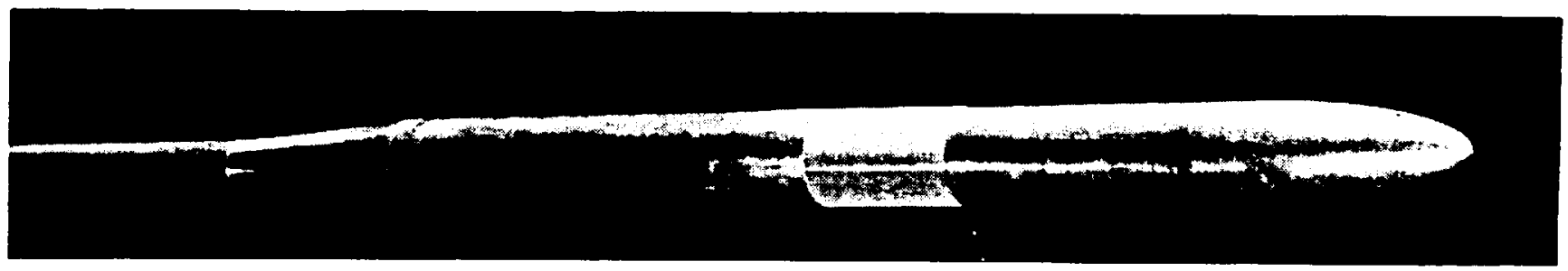

Plate Il Aluminum-model fiber-optic microphone-sensor head made of specialty single mode fiber wound around aerodynamically smooth body of aluminum. 


\section{REPORT DOCUMENTATION PAGE}

Public reporting burden for this collection of intormation is estimated to average 1 hour per response, including the time for reviewing instructions. searching existing date sources, gathering and maintaining the data needed and completing and reviewing the collection of intormation. Send comments regarding this burden estimate or any other aspect of thie allection Davis Highway, Suite 1204. Arlington, VA 22202-4302. and to the Office of Management and Budget. Paperwork Reduction Project (0704-0188). Washington, DC 20503.
1. AGENCY USE ONLY (Leave blank)
2. AEPORT DATE
January 1993
Conference Publication

3. REPORT TYPE AND DATES COVERED

4. TITLE AND SUBTITLE

5. FUNDING NUMBERS

Fiber-Optic Interferometric Sensors for Measurements of Pressure

Fluctuations: Experimental Evaluation

6. AUTHOR(S)

Y. C. Cho and P. T. Soderman

7. PERFORMING ORGANIZATION NAME(S) AND ADDRESS(ES)

8. PERforming organization

REPORT NUMBER

Ames Research Center

Moffett Field, CA 94035-1000

A-93042

9. SPONSORING/MONITORING AGENCY NAME(S) AND ADDRESS(ES)

10. SPONSOAING/MONITOAING AGENCY REPORT NUMBER

National Aeronautics and Space Administration

Washington, DC 20546-0001

NASA TM-104002

\section{SUPPLEMENTARY NOTES}

Point of Contact: Y. C. Cho, Ames Research Center, MS 260-1, Moffett Field, CA 94035-1000; (415) 604-4139

12a. DISTRIBUTION/AVAILABILITY STATEMENT

12b. DISTRIBUTION CODE

Unclassified - Unlimited

Subject Category 06

13. ABSTRACT (Maximum 200 words)

This paper addresses an anechoic chamber evaluation of a fiber-optic interferometric sensor (fiber-optic microphone), which is being developed at NASA Ames Research Center for measurements of pressure fluctuations in wind tunnels.

14. SUBJECT TERMS

Fiber-optic, Sensors, Interferometric

15. NUMBER OF PAGES

Fiber-optic, Sensors, Interferometric

16. PRICE CODE

$\mathrm{A02}$

\begin{tabular}{l|l}
\hline 17. SECURITY CLASSIFICATION & 18. SECURITY CLASSIFICATION \\
OF REPORT & OF THIS PAGE \\
Unclassified & Unclassified \\
\hline
\end{tabular}

19. SECURITY CLASSIFICATION OF ABSTRACT 